\title{
NEUROLOGICAL LETTER FROM
}

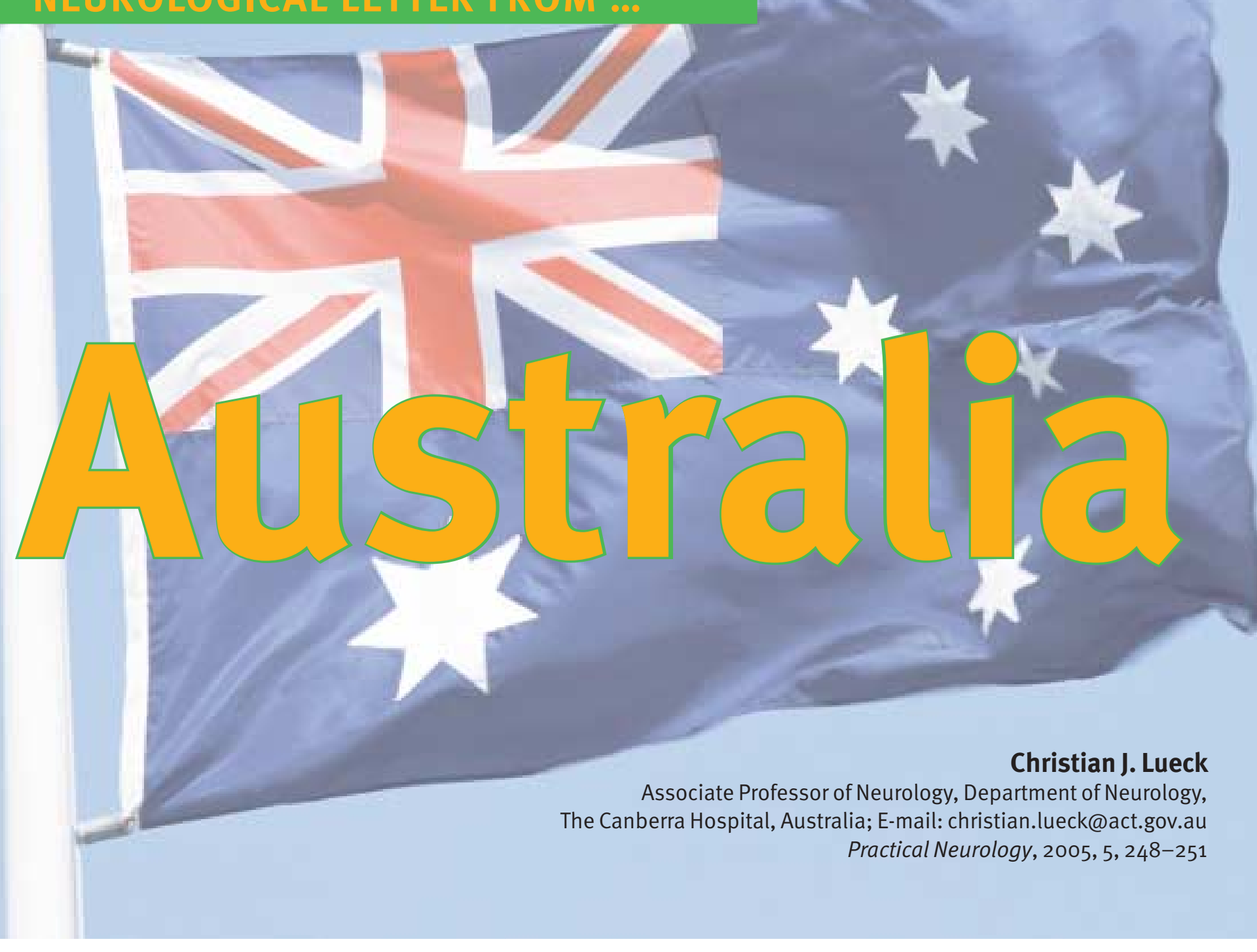

I was a Consultant Neurologist in Edinburgh for almost 9 years before I moved to become a Senior Staff Specialist at the Canberra Hospital in Australia in 2003. This was for a combination of reasons, including the fact that Canberra offered much scope for development and I didn't see too much hope of that in the UK N ational H ealth Service(N HS). Even though Canberra isthe capital of Australia, it is unlikely that many readers will know much about it. It is relatively small, about 350000 people, and though thearea has been populated by theN gunnawal peoplefor at least 21000 years, it was only named Canberra as recently as 1913 when it became the seat of Government for the new Commonwealth of Australia.

Canberraisanaturally beautiful cityand, becauseitisrelatively new, it is very well-organized with an extremely good road system, excellent public services, very good schools, and a relatively low crime-rate. It has two large public hospitals, one in the north and one in the south where neurology is based. All medical and surgical disciplines are represented with the major exception of transplantation surgery, for which patients go to Sydney, about 200 miles to the north-east.

Taking up neurological practice in a different country was somewhat daunting but in fact I have found little difference between the type of patients I see in Canberra and those I saw in Edinburgh. However, moving countries has caused me to reflect on a number of differences in medical practice between the UK (dominated by the NHS) and Australia where there is a much smaller public service.

\section{GETTING HERE}

Moving to Canberra was a bureaucratic challenge which made merealizethequalifications and privileges I had cometo takefor granted in the UK. O bviously, the first hurdle was to obtain the right to resideand work in Australia. This took about 18 months, but was much easier for me because I have an Australian wife. The next hurdle was to have my UK qualifications recognized. The formal way to do this is to sit an examination (written, long 
cases, and short cases) in the whole of general medicine. However, it is possible to obtain limited specialist registration if one has qualifications in a specialty that are recognized as equivalent to Australian qualifications. Assessing this, as expected, involved inspection of my UK qualifications, as well as determining that I could speak English adequately. $\mathrm{H}$ aving passed these hurdles (which took over 6 months), I wasthen invited by theRoyal Australasian College of Physicians to attend an interview at a capital city of my choice. AsI wasin Edinburgh, I rather naïvely suggested London. Unfortunately, thiswasn't quitewhat they meant - I had a choice of a different sort of capital city, i.e. Sydney, M elbourne, Brisbane, etc. The upshot of theinterview - in Sydney - was that my UK qualifications were recognized, but I still had to undergo a year of supervised practice in Australia before I could be given full registration to practise neurology. Therefollowed therather curious situation in which I took up my post as the only Staff Neurologist at my hospital (where I was also both $\mathrm{Head}$ of Department and AssociateProfessor of N eurology) whilebeing 'supervised' by one of my visiting medical officer colleagues.
Even having passed theinterview in Sydney, I still had to obtain local registration with the $\mathrm{H}$ ealth Board to beallowed to practise in Canberra. I then found I had to register with the H ealth Insurance Commission to obtain a 'provider number', which gives me the right to request tests and to qualify for the M edicare rebate when patients come to see me (this differs from my 'prescriber number' which I also had to obtain, but I won't try to explain the difference between these two as there isn't enough space). As I only found out about all this after I arrived in Australia, I spent thefirst few monthsunableto request testssuch as M R scans- my junior staff had to sign the request forms for me.

\section{CLUB MEMBERSHIP}

All these essentially bureaucratic issues made me think about what it is that makes me a neurologist, and what tells the rest of the world that I am (I hope) at least a passably good one. Perhaps somewhat disappointingly, it means basically belonging to a form of neurology 'club' with rather rigorous entry criteria. I don'tmean theAssociation of British N eurologistsor theAustral-

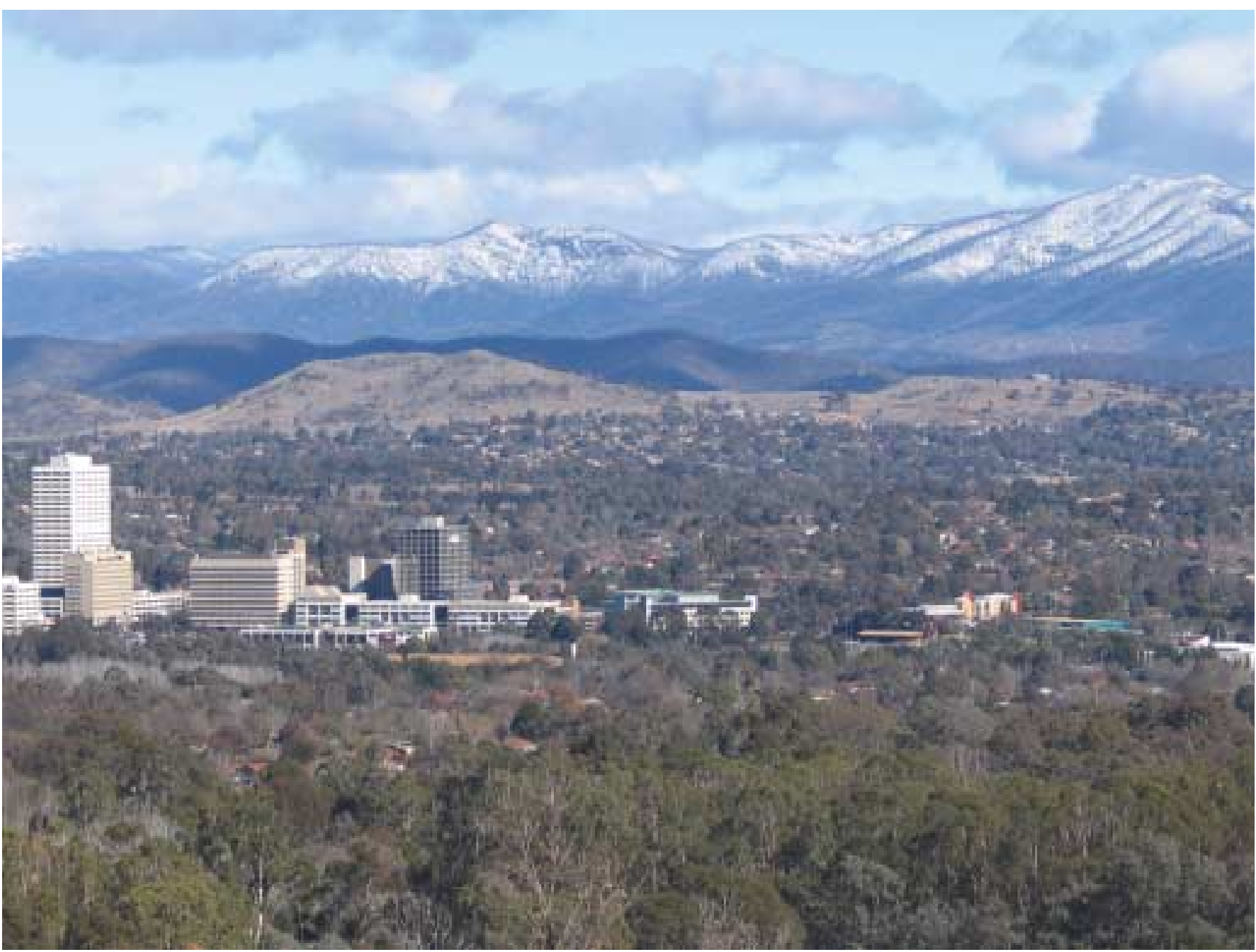

Aerial view of south Canberra. The snow on the mountain tops in the distance may surprise some readers, but we are only a 2- hour drive from the ski slopes. Photograph courtesy of Dr Damian McMahon. 
ian Association of N eurologists ( which areobviously rather select clubs). I mean the Specialist Neurology Registers held by thenational medical regulating bodies where, for neurology, the membership criteria seem to be an 'adequate' clinical training, some form of assessment, and subsequent payment of an annual membership fee. From my personal experience, it appears thatmembership of such aclub in onecountry is transferableto another country if the appropriatemembership criteria of thenew club aremet (and an adequate fee is paid). But I do wonder whether this system could beimproved upon.

Because I am as old as I am, my specialist assessment actually comprises little more than an endorsement in the UK that for the previous 4 years I had worked in 'accredited' neurology training posts. Like most of my contemporaries in the UK and Australia, I was never asked to sit an 'exit' exam, nor have I been assessed on how much neurological knowledge I actually picked up during my training. N evertheless, once I made it into the club, I was let loose on the public, and have never been formally reassessed as to whether I am still practising at an adequatestandard (whatever that means). Even allowing for my year of peer review once I got to Australia, no one appropriately qualified to judgehas ever seen meinter act with a patient or critically tested my diagnostic acumen.
In both the UK and Australia, various committees are at work to improve assessment during training, to explore the possibility of exit exams, and to determine how fitness to continue practising might subsequently be assessed. Much as I now dread the thought of sitting an exam or undertaking some other form of revalidation exercise, I have to concede that this is what we should all be heading towards. Though I know it will complicate matters, I would strongly suggest that it would be a good idea if there were some form of international dialogue in this process. By means of adopting mutually agreed criteria, continuing assessment could become internationally standardized. This would greatly facilitate the movement of suitably qualified and revalidated doctorsfrom onecountry to another by reducing the sort of bureaucracy that I had to work my way through to get here.

\section{NEUROLOGYTRAINING}

In Australia, like the UK, neurology training begins after passing a qualifying postgraduate exam, which is taken after a minimum of 3 years in general medicine. The UK training in neurology then comprises 5 years of specialist experience. The Australian training comprises only 3 years- two coreyearsand an elective. The two coreyears are standard, 'coal face' jobs. The

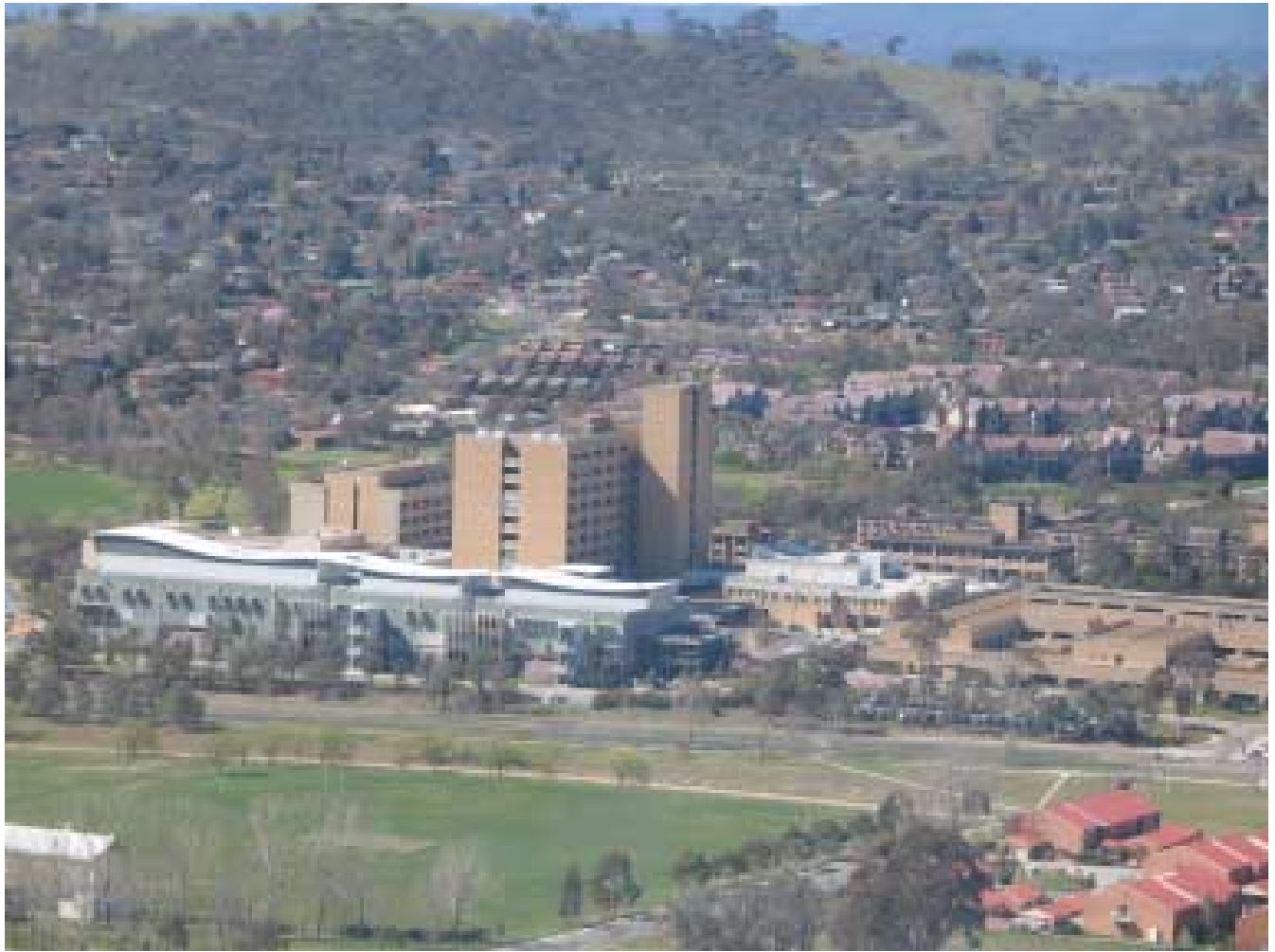

The Canberra Hospital. Photograph courtesy of $\mathrm{Dr}$ Damian McMahon. 
elective year is much more flexible, often spent in basic neuroscience research, or attached to specialist stroke, epilepsy, neurophysiology, or movement disorder units, sometimes abroad. $M$ any trainees then spend a year or two as a clinical fellow (again, often in another country) before taking up a consultant post, but this is not, strictly speaking, necessary.

Onemajor difference between the two countries is the neurophysiology component of training. In the UK, neurology trainees have to spend a'period of time' doing neurophysiology, sitting in with a consultant and 'getting a feel' for what is involved. In Australia, the requirements are much more precise, and the trainees have to report on $500 \mathrm{EEGs}$ and 50 evoked potentials, and perform 250 nerveconduction studies. This reflects the fact that neurologists in Australia are also neurophysiologists (though they vary greatly in how much they do), in contrast to the UK where neurologists and neurophysiologists arereally two distinct types of doctor with separatetraining programmes and separate specialist registers.

Neurophysiology was therefore my biggest worry when moving to Australia. Rather dauntingly, one of the requirements in Canberra was to report on EEGs, and to hold a regular EM G clinic. To cope with this, I went on several 'crash revision' courses when I first moved here, but it still took several months beforel felt I was competent and I still very firmly limit myself to all but the most basic nerveconduction studies.

\section{NEUROLOGY PRACTICE}

In theUK, thereare470neurologists, in Australia, just under 400. At first sight, it might seem that Australia is doing rather well, considering the population of the UK is about 55 million, while that of Australiaisonly 20 million. H owever, Australiahasaland-massthat isaboutthesizeof continental Europe, meaning that many Australians who don't live in themajor cities find accessing a neurologist very difficult, if not impossible. Also, in the UK many neurologists have relatively little to do with themanagement of acutestroke. This is most unusual in Australia, where, for the majority of neurologists, strokemakes up thelargest part of their in-patient workload.

Curiously, theUK has a much larger number of neurology trainees - currently 241. In Australia, therearefewer than 50. Even allowing for the difference in length of the respective training, this is a significant difference. Maybe my earlier suggestion of 'globalization' of qualifica- tion recognition might be useful if the UK ends up with a surfeit of trained neurologists and Australia a dearth.

Perhapsthebiggest differencein neurological practice is the public/private divide. In theUK, almost all neurologists are attached to an NHS hospital where they spend all or most of their time - although many neurologists have a private practice in addition to their $\mathrm{NHS}$ commitment, their energies and organizational skills are, for the most part, directed towards serving and supporting the public system. In Australia, the equivalent would be the Hospital Staff Specialists, most of whom al so do a small amount of privatepractice. H owever, most neurologistsare private practitioners who have contracts with the public hospitals as 'Visiting M edical Officers' (VM Os). In my hospital, there are two staff specialists and three VM Os, and between us we run a one in five on-call rota. VM Os are contracted in different ways in different hospitals, but Canberra generally expects about $9 \mathrm{~h} /$ week from each of ours. Thus, it is not too surprising that VM Os' energies and organizational skills are mostly directed to their practices, not to the public hospitals. For a largenumber of reasons, I think thisisa pity, and Australia isthepoorer as a result. In spite of its many faults, the UK really does havean enormous asset in the N HS.

\section{EPILOGUE}

I feel greatly privileged to have had the opportunity to live in both the UK and Australia, and to have been able to work as a neurologist in both countries. There are many differences in life-style, some good, some not so good. I love the UK, and I very much enjoyed working in Edinburgh, but for me there is greater opportunity over here, and nothing beats sitting on the veranda of our weekender at the coast, glass in hand, listening to the gentle cacophony of Australian birdsong while watching the waves gently roll in from the Pacific Ocean as the sun sets over the eucalyptus-clad mountains in the background.

\section{ACKNOWLEDGEMENTS}

I am very grateful to Mandy Jones of the Australian Association of Neurologists and Susan Tann of the Association of British Neurologists for providing me with information about the numbers of neurologists and trainees in their respectivecountries, and to Drs LataVadlamudi and Roger Tuck for their helpful comments on thetext. 